\title{
CONSUMO E DESEMPENHO DE BOVINOS DE APTIDÃO LEITEIRA EM CONFINAMENTO ALIMENTADOS COM GLICEROL
}

\author{
Jean Pacheco Leão ${ }^{1}$, Jose NeUman MiRanda Neiva ${ }^{2}$,JoÃo Restle ${ }^{3}$, Pedro Veiga Rodrigues \\ PAUlino $^{4}$, Aline Evangelista Machado Santana ${ }^{1}$, Fabricia Rocha Chaves MiotTo ${ }^{2}$, Regis \\ LuISMíssio
}

\author{
${ }^{1}$ Pós-graduando da Universidade Federal do Tocantins, Araguaína, TO, Brasil. \\ ${ }^{2}$ Professores Doutores da Universidade Federal do Tocantins, Araguaína, TO, Brasil. - araguaia2007@ gmail.com \\ ${ }^{3}$ Professor Visitante Nacional Sênior (CAPES) na Universidade Federal do Tocantins, Araguaína, TO, Brasil \\ ${ }^{4}$ Professor doutor da Universidade Federal de Viçosa, Viçosa, MG, Brasil \\ ${ }^{5}$ Pós-doutorando da Universidade Federal do Tocantins, Araguaína, TO, Brasil
}

O trabalho foi desenvolvido objetivando-se avaliar o consumo de nutrientes e desempenho produtivo de vacas e novilhos de aptidão leiteira, alimentados com dietas contendo glicerol. Os animais foram distribuídos em um delineamento experimental inteiramente casualizado, com arranjo fatorial de $4 \times 2(0,6,12$ e $24 \%$ de glicerol $x$ sexos - vacas e novilhos) e três repetições. Foi observado que os consumos de matéria seca (MS), proteína bruta(PB) e carboidratos não fibrosos (CNF)não foram afetados pela inclusão do glicerol às dietas de vacas e novilhos. Houve diminuição linear no consumo de fibra em detergente neutro (FDN) (g/kg de PC) para as vacas; no entanto, os consumos de FDN e extrato etéreo (EE) dos novilhos não foram afetados quando expressos em $\mathrm{kg} / \mathrm{dia}$, mas apresentaram comportamento quadrático para o consumo de FDN expresso em \%PC e diminuição linear para o consumo deEE expressos em $\mathrm{g} / \mathrm{kgPC}^{0,75^{5}}$ e \%PC. As vacas apresentaram maior consumo de MS, PB, FDN, CNF expressos em $\mathrm{kg} /$ dia que os novilhos, quando se incluiu 6 e $12 \%$ de glicerol às dietas, e maior consumo de MS, FDN e CNF expressos em $\mathrm{g} / \mathrm{kg} / \mathrm{PC}^{0,75}$, quando se incluiu $6 \%$ glicerol às dietas. $\mathrm{O}$ ganho de peso diário não foi afetado pela inclusão do glicerol. Conclui-se que o glicerol pode ser incluído em até $24 \%$ da MS total das dietas de novilhos e vacas de aptidão leiteira sem comprometer o desempenho dos animais.

PALAVRAS-CHAVE:glicerina bruta; subprodutos do biodiesel; valor nutritivo.

\section{CONSUMPTION AND PERFORMANCE OF DAIRY CATTLE IN CONFINEMENTFED WITH GLYCEROL}

\section{ABSTRACT}

This study was conducted to evaluate the nutrients intake and the productive performance ofdairy cows and steers fed diets containing glycerol. The animals were distributed in a completely randomized design with factorial arrangement 4 glycerol levels (0, 6, 12 and 24\%) $\mathrm{x} 2$ sexes (steers and cows) and three replications. The consumption of dry matter (DM) crude protein (CP) and non-fiber carbohydrates (NFC) were not affected by inclusion of glycerol in the diets of cows and steers.However, there was a linear decrease in the consumption of neutral detergent fiber (NDF) $(\mathrm{g} / \mathrm{kg} \mathrm{BW})$ for cows, but it did not affect the consumption of NDF and ethereal extract (EE) for steers when expressed in $\mathrm{kg} /$ day, but showed a quadratic response to NDF intake expressed as\%BW and a linear decrease for the consumption of EE expressed in $\mathrm{g} / \mathrm{kgBW}^{0.75}$ and $\% \mathrm{BW}$. The cows showed a higher intake of DM, CP, NDF, NFC, expressed in $\mathrm{kg} / \mathrm{day}$, than the steers, when the diets included 6 and $12 \%$ glycerol and higher intakes of DM, $\mathrm{NDF}$ and $\mathrm{NFC}$, expressed in $\mathrm{g} / \mathrm{kg} / \mathrm{BW}^{0.75}$, when diet included $6 \%$ glycerol. The daily weight gain was not affected by the inclusion of glycerol. We concluded that glycerol can be included up to $24 \%$ of total DM of diets ofdairy steers and cows without compromising animal 
performance.

KEYWORDS: biodiesel byproducts; crude glycerin; nutritional value.

\section{INTRODUÇÃO}

No Brasil, o abate de animais terminados em confinamento, apesar de ser considerado pequeno em relação ao de outros países, contabilizou, em 2010, aumento de aproximadamente $15 \%$ em relação ao ano de 2009, totalizando 3.450 .717 bovinos abatidos (BANCO ORIGINAL, 2012). De acordo com SIMAS et al.(2008), maiores interesses em confinar bovinos leiteiros ou de corte nos últimos anos provêm do aumento da disponibilidade de grãos no mercado e do aumento das alternativas alimentares para compor as rações, favorecendo a diminuição dos custos com alimentação dos animais, fato que torna a atividade mais viável economicamente (ROCHA et al., 2006).

Dentre os alimentos alternativos para alimentação animal, o glicerol vem se tornando uma alternativa promissora, sendo alvo de estudos devido à sua similaridade energética com $\mathrm{o}$ milho (DONKIN, 2008). O glicerol é um produto derivado do processo de transesterificação de óleos e gorduras, sendo o seu rendimento equivalente a aproximadamente $10 \%$ da produção do biodiesel (ABDALLA et al., 2008; DONKIN, 2008; MOTTA et al., 2009; SWIATKIEWICZ \& KORELESKI, 2009). Com os incentivos do Governo brasileiro através do Programa Nacional de Produção e Uso de Biodiesel, está prevista a adição de $5 \%$ de biodiesel ao diesel fóssil, sendo necessária aproximadamente a produção de 2,5 bilhões de litros de biodiesel até 2013, o que também aumenta a oferta de glicerol (ABDALLA et al., 2008), a qual já vem superando a capacidade da sua utilização desde 2007 pelas indústrias brasileiras (ABIQUIM, 2007), tornando-se então um potencial agente poluidor.

A utilização do glicerol na alimentação de bovinos é conhecida desde a década de 1950 (DONKIN et al., 2009) como agente medicamentoso, preventivo da cetose em vacas leiteiras, devido às suas características gliconeogênicas, tendo, assim, a maior parte dos estudos baseados principalmente no acréscimo de pequenas quantidades na ração (CHUNG et al., 2007; DEFRAIN et al., 2004) e não no uso como macroingrediente na ração total (DONKIN et al., 2009). Entretanto, recentemente, com o aumento da oferta de glicerol, as pesquisas têm direcionado o foco para a utilização desse composto como alimento, almejando incluí-lo em maior quantidade na ração. Para isso, devem ser elucidados os níveis de inclusão ideais para diferentes categorias, de modo que não se restrinja o consumo, e maximize o desempenho dos animais ou reduza os custos com a alimentação.

Nesse sentido, o presente estudo foi desenvolvido objetivando avaliar o consumo e o desempenho produtivo de vacas e novilhos alimentados com dietas contendo glicerol.

\section{MATERIAL E MÉTODOS}

Foram avaliadas quatro dietas contendo 0, 6, 12 e $24 \%$ de inclusão de glicerol $\left(\right.$ GENPA $^{\circledR}$ Glicerol Energético Nutricional para Alimentação Animal). O glicerol utilizado foi oriundo do processo de transesterificação do óleo de soja e a rota metílica e o hidróxido de sódio foram usados como catalisadores. Foram utilizados 24 bovinos de aptidão leiteira, em confinamento, sendo 12 vacas com idade média de 60 meses, com peso inicial médio de $466 \mathrm{~kg}$, e 12 novilhos castrados com idade média de 30 meses e com peso inicial médio de 347 $\mathrm{kg}$, distribuídos em delineamento experimental inteiramente casualizado (DIC), em arranjo fatorial $4 \times 2$ (níveis de inclusão x classes sexuais) com três repetições por tratamento.

O glicerol utilizado para a elaboração das dietas apresentou $89,92 \%$ de matéria seca (MS); $1,19 \%$ de extrato etéreo (EE); $7,86 \%$ de matéria mineral (MM); 80,35\% de glicerol; $<0,01 \%$ de metanol e 7,47\% de cloretos, com a densidade de $1,27 \mathrm{~g} / \mathrm{cm}^{3}$, devidamente registrado no Ministério da Agricultura Pecuária e Abastecimento (MAPA) pela Empresa GRANOL SA.

No início do experimento, os animais foram identificados com brincos, tratados contra endo e ectoparasitas, suplementados com complexo vitamínico ADE e colocados em baias individuais (6 $\mathrm{m}^{2}$ ) cobertas, com piso cimentado, cocho de alimentação e bebedouro.

Os animais permaneceram confinados por 84 dias, sendo 14 dias para adaptação às dietas, manejo e instalações, seguidos pelo período experimental de 70 dias. Os animais foram pesados no início e no final do experimento, sempre pela manhã, antes do fornecimento das dietas e sem jejum prévio para a determinação do ganho de peso total (GPT) e ganho de peso diário (GPD).

As dietas foram formuladas para conter $20 \%$ 
de volumoso (silagem de capim elefante Pennisetum purpureum) e $80 \%$ de concentrado composto por milho, farelo de soja, glicerol, ureia, calcário e sal mineral (Tabela 1), de forma que as mesmas fossem isoproteicas (13\% de PB). Devido à presença de cloretos noglicerol, a quantidade de $\mathrm{NaCl}$ das dietas foi corrigida com a utilização de uma mistura mineral contendo cloreto de sódio e outra sem esse componente (Tabela 1).

Tabela 1 - Proporção dos ingredientes e composição química das dietas experimentais em função dos níveis de inclusão de glicerol

\begin{tabular}{|c|c|c|c|c|c|}
\hline \multirow{2}{*}{ INGREDIENTES } & & \multicolumn{4}{|c|}{ Nível de glicerol na dieta (g/kg MS) } \\
\hline & & 0 & 60 & 120 & 240 \\
\hline Calcário & & 5,7 & 6,8 & 6,1 & 4,7 \\
\hline Farelo de soja $49 \%$ & & 110,5 & 110,0 & 110,0 & 110,0 \\
\hline Milho grão seco & & 663,8 & 611,4 & 550,0 & 427,3 \\
\hline Silagem & & 200,0 & 200,0 & 200,0 & 200,0 \\
\hline Ureia & & 0,0 & 1,0 & 3,9 & 8,0 \\
\hline Glicerol & & 0,0 & 60,0 & 120,0 & 240,0 \\
\hline \multirow[t]{3}{*}{ Mistura mineral } & & $20,0 *$ & $10,0 * *$ & $10,0^{* *}$ & $10,0^{* *}$ \\
\hline & & \multicolumn{4}{|c|}{ Composição Bromatológica (g/kg MS) } \\
\hline & Silagem & 0 & 60 & 120 & 240 \\
\hline Materia Seca & 252,6 & 738,9 & 724,2 & 730,7 & 732,9 \\
\hline Proteina Bruta & 62,9 & 141,0 & 140,2 & 140,3 & 141,3 \\
\hline Fibra em detergente neutro & 749,0 & 231,9 & 225,3 & 216,9 & 201,1 \\
\hline Fibra em detergente ácido & 501,6 & 134,1 & 131,5 & 130,9 & 124,4 \\
\hline Hemicelulose & 247,4 & 97,8 & 93,7 & 86,0 & 76,7 \\
\hline Lignina & 62,0 & 14,9 & 15,1 & 15,0 & 15,3 \\
\hline Celulose & 388,9 & 106,9 & 108,0 & 108,0 & 106,3 \\
\hline Nitrogênio insolúvel em detergente neutro ${ }^{1}$ & 284,7 & 141,6 & 134,1 & 128,8 & 103,8 \\
\hline Nitrogênio insolúvel em detergente ácido & 158,4 & 108,7 & 91,5 & 95,0 & 82,4 \\
\hline Extrato Etéreo & 15,7 & 21,1 & 18,9 & 18,5 & 17,5 \\
\hline Cinzas & 123,2 & 70,3 & 65,7 & 67,1 & 77,0 \\
\hline Carboidratos não fibrosos & 49,2 & 535,6 & 549,9 & 557,2 & 563,2 \\
\hline Carboidratos Totais & 798,2 & 767,5 & 775,2 & 774,1 & 764,3 \\
\hline Nutrientes digestíveis totais & 452,5 & 738,2 & 742,4 & 741.7 & 736,4 \\
\hline
\end{tabular}

O NDT das dietas foi calculado segundo o NRC (2001) pela equação de predição,NDTm = $\{\mathrm{CNFdv}+\mathrm{PBdv}+(2,25 \times \mathrm{AGdv})+\mathrm{FDNdv}\}-7$, onde:CNFdv, PBdv, AGdv e FDN dv são obtidos por meio das seguintes equações:CNF verdadeiramente digestível $=0,98 \times$ CNF $\times$ PAF;PB verdadeiramente digestível (para forragens) $=50 \mathrm{~PB} \times \exp \{-1,2 \times$ (PIDA / PC) $\} ; \mathrm{PB}$ verdadeiramente digestível (para concentrados $)=\{1-(0,4 \times(\mathrm{PIDA} / \mathrm{PB}))\} \times \mathrm{PB} ; \mathrm{AG}$ verdadeiramente digestível $=(\mathrm{EE}-1)$, se $\mathrm{EE}<1$, então $\mathrm{AG}=0 ; \mathrm{FDN}$ verdadeiramente digestível $=0,75 \mathrm{x}$ $(\mathrm{FDNn}-\mathrm{L}) \times\{1-(\mathrm{L} / \mathrm{FDN}) 0,667\}$, onde:PIDA = nitrogênio insolúvel em detergente ácido x 6,25; $\mathrm{AG}=$ ácidos graxos, $\mathrm{L}=$ lignina;FDNn $=$ FDN - PIDN, PIDN = nitrogênio insolúvel em detergente neutro $\mathrm{x}$ 6,$25 ; \mathrm{PAF}=$ fator de ajuste para processamento
(NRC, 2001); neste caso, utilizou-seo fator 1, para a silagem de capim elefante bem como para as raçõesconcentradas.

A adição do glicerol à ração concentrada foi feita momentos antes do fornecimento de forma a deixar o concentrado o mais homogêneo possível. Após a mistura do glicerol à ração concentrada, a mesma foi misturada à silagem para fornecimento nos cochos.

As dietas foram fornecidas duas vezes ao dia, às 9:00 e 16:00h, e as sobras pesadas diariamente pela manhã de modo a ajustar a oferta em nível que permitisse sobras de aproximadamente $10 \%$ do total ofertado. Os animais tiveram acesso livre e irrestrito à água de boa qualidade.

Os alimentos fornecidos e as sobras foram 
amostrados semanalmente, em dias pré-determinados, identificados, acondicionados em sacos plásticos e congelados. Posteriormente, as amostras foram descongeladas em temperatura ambiente e foram agrupadas a cada duas semanas formando uma amostra composta para cada período de 14 dias. As amostras compostas foram pré-secas em estufa ventilada a $55^{\circ} \mathrm{C}$ por aproximadamente 72 horas, sendo, em seguida, moídas e acondicionadas em frascos com tampas para análisesposteriores.

As análises bromatológicas foram realizadas no Laboratório de Nutrição Animal da Universidade Federal do Tocantins, Campus da Escola de Medicina Veterinária e Zootecnia(EMVZ), localizada no município de Araguaína-TO.

Os teores de matéria seca (MS) e proteína bruta (PB)foram determinados nas amostras das rações fornecidas e das sobras,segundo descrito por SILVA \& QUEIROZ (2002).

Para a determinação do teor de extrato etéreo (EE), utilizou-se a metodologia da AOCS (2009),na qual as amostras foram colocadas em sacos XT4 (Ankom®) e submetidas à extração em alta temperatura, utilizando-se o equipamento XT10 (Ankom $\left.{ }^{\circledR}\right)$ e empregando-se éter de petróleo como solvente. A fibra em detergente neutro (FDN), fibra em detergente ácido (FDA), hemicelulose (HEM), nitrogênio insolúvel em detergente ácido (NIDA), nitrogênio insolúvel em detergente neutro (NIDN) e lignina foram determinados conforme metodologia proposta por Van SOEST et al. (1991). Os carboidratos totais (CT) e os carboidratos nãofribrosos (CNF) foram calculados segundo SNIFFENet al. (1992), em que CT $=100-(\% \mathrm{~PB}+$ $\% \mathrm{EE}+\% \mathrm{CZ}$ ) e $\mathrm{CNF}=\mathrm{CT}-\mathrm{FDN}$.
Foram avaliados os consumos de MS, PB, FDN, CNF e EE,bem como o ganho de peso diário (GPD).

Os dados foram analisados estatisticamente por meio do programa SISVAR ${ }^{\circledR}$ (FERREIRA, 2003). Análise de variância foi realizada para todas as variáveis, sendo estas avaliadas por regressão, em função dos níveis de inclusão de glicerol, com nível de significância de 5\% de probabilidade de erro. O coeficiente de determinação $\left(\mathrm{R}^{2}\right)$ de cada análise foi calculado com base somente nos dados médios. A comparaçãoentre as classes sexuais sob cada nível foi efetuada pelo teste de $\mathrm{F}$ a $5 \%$ de probabilidade de erro.

\section{RESULTADOS E DISCUSSÃO}

Os consumos de matéria seca (CMS) expressos em $\mathrm{kg} / \mathrm{dia}, \mathrm{g} / \mathrm{kgPC}^{0,75} \mathrm{e} \mathrm{g} / \mathrm{kg}$ de $\mathrm{PC}$ não foram alterados $(P>0,05)$ pela inclusão de glicerol às dietas, independentemente da classe sexual (Tabela 2). No entanto, ao se comparar o consumo de matéria seca expresso em $\mathrm{kg} / \mathrm{dia}$ das vacas em relação aos novilhos, observou-se que as vacas alimentadas com dietas contendo 6 e $12 \%$ de glicerol consumiram, respectivamente, 4,9 e $3,5 \mathrm{~kg}$ de $\mathrm{MSa}$ mais que os novilhos. Porém, quando o consumo foi expresso em $\mathrm{g} / \mathrm{kgPC}^{0,75}$ observou-se diferença apenas para a inclusão de $6 \%$ de glicerol.

O maior CMS observado para as vacas, quando expresso em $\mathrm{kg} / \mathrm{dia}$, é explicável pelo fato de esses animais apresentarem maior peso vivo inicial. Essa constatação é evidenciada pelo CMS expresso em $\mathrm{g} / \mathrm{kg}$ de PC não diferir entre as duas categorias.

Tabela 2 - Médias, equações de regressão, coeficiente de variação $(\% \mathrm{CV})$ e nível de significância $(P)$, para os consumos médios diários de matéria seca (MS) e proteína bruta (PB) em função dos níveis de glicerol nas dietas

\begin{tabular}{|c|c|c|c|c|c|c|c|c|c|}
\hline \multirow[b]{2}{*}{ Item } & \multirow[b]{2}{*}{ Sexo } & \multicolumn{4}{|c|}{ Níveis de glicerol (g/kg MS) } & \multirow[b]{2}{*}{ Média } & \multirow[b]{2}{*}{ Regressão } & \multirow[b]{2}{*}{ CV\% } & \multirow[b]{2}{*}{$P$} \\
\hline & & 0 & 60 & 120 & 240 & & & & \\
\hline \multicolumn{10}{|c|}{ MS } \\
\hline \multirow{2}{*}{$\mathrm{kg} / \mathrm{dia}$} & VAC & $14,42 \mathrm{a}$ & $14,61 \mathrm{a}$ & $13,39 a$ & $12,88 \mathrm{a}$ & 13,82 & $\hat{\mathrm{Y}}=14,59^{\mathrm{NS}}$ & 15,85 & 0,98 \\
\hline & NOV & $11,53 \mathrm{a}$ & $9,71 b$ & $9,89 \mathrm{~b}$ & $10,51 \mathrm{a}$ & 10,41 & $\hat{\mathrm{Y}}=11,37^{\mathrm{NS}}$ & & 0,28 \\
\hline \multirow[t]{2}{*}{$\mathrm{g} / \mathrm{kgPC} \mathrm{C}^{0,75}$} & VAC & $129,94 \mathrm{a}$ & $133,63 \mathrm{a}$ & $127,73 \mathrm{a}$ & $120,16 \mathrm{a}$ & 127,87 & $\hat{\mathrm{Y}}=130,84^{\mathrm{NS}}$ & 11,24 & 0,64 \\
\hline & NOV & $127,04 \mathrm{a}$ & $105,74 b$ & $111,01 \mathrm{a}$ & $112,91 \mathrm{a}$ & 114,17 & $\hat{Y}=124,63^{N S}$ & & 0,40 \\
\hline \multirow[t]{2}{*}{$\mathrm{g} / \mathrm{kg} \mathrm{PC}$} & VAC & 27,0 & 28,0 & 27,1 & 25,3 & 26,8 & $\hat{\mathrm{Y}}=27,2^{\mathrm{NS}}$ & 10,64 & 0,52 \\
\hline & $\mathrm{NOV}$ & 28,3 & 23,4 & 24,9 & 24,9 & 25,4 & $\hat{\mathrm{Y}}=27,7^{\mathrm{NS}}$ & & 0,15 \\
\hline \multicolumn{10}{|c|}{ PB } \\
\hline \multirow[t]{2}{*}{$\mathrm{kg} / \mathrm{dia}$} & VAC & $1,99 \mathrm{a}$ & $1,99 \mathrm{a}$ & $1,83 \mathrm{a}$ & $1,76 \mathrm{a}$ & 1,89 & $\hat{\mathrm{Y}}=2,01^{\mathrm{NS}}$ & 15,86 & 0,96 \\
\hline & NOV & $1,59 \mathrm{a}$ & $1,33 b$ & $1,36 \mathrm{~b}$ & $1,43 \mathrm{a}$ & 1,43 & $\hat{\mathrm{Y}}=1,57^{\mathrm{NS}}$ & & 0,28 \\
\hline
\end{tabular}

Médias na mesma coluna, seguidas de letras distintas, diferem entre si pelo teste de $\mathrm{F}$ a $5 \%$ de probabilidade de erro. ${ }^{\text {NS }}$ - não significativo. VAC: Vaca; NOV: Novilho.

O CMS é um fator determinante para o desempenho produtivo dos animais e demonstra-se 
no presente estudo que o glicerol pode ser utilizado até o nível de $24 \%$ da MS total da dieta sem comprometer a ingestão de MS. Os resultados aqui observados estão de acordo com os dados obtidos por MUSSELMAN et al. (2008) de que somente a partir de $30 \%$ de inclusão de glicerina bruta o CMS de ovinos decresceu.

Entretanto, PARSONS et al. (2009) observaram redução no CMS em novilhas alimentadas com dietas contendo até $16 \%$ de glicerina bruta e sugeriram que o alto nível de concentrado na dieta $(960 \mathrm{~g} / \mathrm{kg}$ MS) era um fator desfavorável ao ambiente ruminal, sendo o referido problema agravado com a adição de glicerol que é isento de fibra. Segundo TRABUE et al. (2007), o acúmulo de lactato no rúmen afeta diretamente as rotas de fermentação do glicerol pelos microrganismos ruminais e, com isso, o consumo é alterado. As respostas obtidas no trabalho realizado por PARSONS et al. (2009) revelam que o problema relacionado ao uso do glicerol pode, na verdade, ser em função do excesso de concentrado na dieta. Tal situação não foi observada no presente ensaio, possivelmente, devido à maior porcentagem de volumoso na dieta em relação ao trabalho supracitado, o que sugere a possibilidade de inclusões de glicerol até o nível de $24 \%$, desde que o fornecimento de fibra efetiva seja assegurado.

Diferentemente do observado no presente estudo, LAGE et al. (2010) observaram diminuição linear no CMS expresso g/dia e g/ kg PC de ovinos alimentados com dietas com relação concentrado:volumoso de 70:30 e inclusões de 0, 3, 6 e $12 \%$ de glicerina bruta. Segundo os autores, a diminuição ocorreu principalmente devido à alta percentagem de ácidos graxos totais $(46,48 \%)$ encontrados na glicerina bruta utilizada.

Desta forma, fica claro que os resultados obtidos com a utilização de glicerol dependem de vários fatores, como o grau de pureza do material, determinante para se obter resultados positivos. No presente estudo, o produto utilizado apresentava baixo percentual de ácidos graxos $(1,19 \%)$ e,por isso, não se observaram limitações no CMS até o nível de inclusão de $24 \%$.

A inclusão de glicerol não alterou o consumo de $\mathrm{PB}$ expresso em kg/dia, g/ $\mathrm{kgPC}^{0,75}$ e $\mathrm{g} / \mathrm{kg}$ de $\mathrm{PC}$ quando este foi adicionado às dietas $(\mathrm{P}>0,05) \mathrm{em}$ função de as dietas terem sido isoproteicas e de não ter havido variação no CMS (Tabela 2). Porém, as vacas alimentadas com dietas contendo 6 e $12 \%$ de inclusão de glicerol consumiram 49 e 35\%, respectivamente, a mais de $\mathrm{PB}$ expressa em $\mathrm{kg} / \mathrm{dia}$ $(\mathrm{P}<0,05)$ que os novilhos.

$\mathrm{O}$ maior consumo de $\mathrm{PB}$ expresso em $\mathrm{kg} / \mathrm{dia}$ pelas vacas nas dietas contendo 6 e $12 \%$ de glicerol é explicado pelo maior consumo de MS das mesmas quando alimentadas com tais dietas. $\mathrm{O}$ entanto, ao se comparar o consumo de $\mathrm{PB}$ em $\mathrm{g} / \mathrm{kg}$ de $\mathrm{PC}$, essa diferença não foi observada $(\mathrm{P}>0,05)$ devido ao CMS em $\mathrm{g} / \mathrm{kg}$ de PC ter sido semelhante entre vacas e novilhos.

Diferente dos resultados do presente estudo, LAGE et al. (2010) observaram consumo de PB, expresso em $\mathrm{g} / \mathrm{dia}$ de $\mathrm{PB}$, decrescente à medida que se incluía glicerina bruta a dietas de ovinos, e justificaram essa diminuição pela menor ingestão de MS, uma vez que as dietas eram isoproteicas.

A inclusão de glicerol às dietas das vacas causou diminuição linear $(\mathrm{P}<0,05)$ no consumo de FDN expresso em $\mathrm{g} / \mathrm{kg}$ de $\mathrm{PC}$ e para os novilhos, redução no consumo expresso em $\mathrm{g} / \mathrm{kg}$ de $\mathrm{PC}$ $(\mathrm{P}<0,05)$ até o nível de 8,33\% de adição (Tabela 3).

Ao se comparar o consumo de FDN expresso em $\mathrm{kg} / \mathrm{dia}$ das vacas com o consumo dos novilhos, constatou-se que as vacas alimentadas com as dietas contendo 6 e $12 \%$ de inclusão de glicerol consumiram, respectivamente, $1,17 \mathrm{e} 0,85 \mathrm{~kg} / \mathrm{dia}$ de FDN a mais que os novilhos, resposta notadamente associada ao maior consumo de MS das vacas, conforme discutido anteriormente.

Ao se observar a composição bromatológica das dietas utilizadas no presente estudo (Tabela 1), verificou-se que a dieta padrão $(0 \mathrm{~g} / \mathrm{kg}$ de $\mathrm{MS}$ de glicerol) a qual possui maior teor de FDN (231.9 $\mathrm{g} / \mathrm{kg}$ de MS), apresenta valor inferior ao mínimo recomendado pelo NRC (2001), que é de $250 \mathrm{~g} / \mathrm{kg}$ de MS com pelo menos $190 \mathrm{~g} / \mathrm{kg}$ de MS oriundo da porção de volumoso. Entretanto, para o tempo de confinamento utilizado neste trabalho, não foram observados disfunções digestivas nos animais devido ao baixo teor de FDN das dietas. De acordo com MERTENS (1997) e JOBIM \& SANTOS (2008), a saúde dos ruminantes depende diretamente de concentrações mínimas de fibra na ração que permitam manter a atividade de mastigação e motilidade do rúmen evitando alterações fermentativas que possam levar à acidose ruminal severa.

A inclusão de glicerol não alterou o consumo de CNF de machos e fêmeas $(\mathrm{P}>0,05)$ expressos em $\mathrm{kg} / \mathrm{dia}, \mathrm{g} / \mathrm{kgPC}^{0,75}$ e \%PC (Tabela 2). Contudo, ao se comparar o consumo de CNF de vacas e novilhos, constatou-se que as vacas consumiram 2,63 e 1,86 kg de CNF a mais que os novilhos $(\mathrm{P}<0,05)$ nos tratamentos com 6 e 12\% de inclusão de glicerol, o que possivelmente ocorreu devido ao maior consumo em $\mathrm{kg} / \mathrm{dia}$ de MS pelas vacas em relação aos novilhos nos respectivos tratamentos. Todavia, a influência dos níveis de inclusão em relação ao sexo dos animais (vacas $\mathrm{x}$ novilhos) ocorreu apenas para animais alimentados com dietas contendo 6\% de 
glicerol. As vacas consumiram $15,05 \mathrm{~g} / \mathrm{kgPC}^{0,75} \mathrm{de}$ CNF a mais que os novilhos, porém, tais diferenças não foram observadas quando os consumos de $\mathrm{CNF}$ foram expressos em \%PC (Tabela 3).

Tabela 3- Médias, nível de significância (P) e erro padrão da média (EPM), para os consumos médios diários de matéria seca (MS), proteína bruta (PB), fibra em detergente neutro (FDN), carboidratos não fibrosos $(\mathrm{CNF})$, extrato etéreo (EE)e ganho de peso diário (GPD) em função dos níveis de glicerol nas dietas

\begin{tabular}{|c|c|c|c|c|c|c|c|c|c|}
\hline \multirow[b]{2}{*}{ Item } & \multirow[b]{2}{*}{ Sexo } & \multicolumn{4}{|c|}{ Níveis de glicerol (g/kg MS) } & \multirow[b]{2}{*}{ Média } & \multirow[b]{2}{*}{ Linear } & \multirow[b]{2}{*}{ Quadrática } & \multirow[b]{2}{*}{$E P M$} \\
\hline & & 0 & 60 & 120 & 240 & & & & \\
\hline \multicolumn{10}{|c|}{ Fibra em Detergente Neutro } \\
\hline \multirow[t]{2}{*}{$\mathrm{g} / \mathrm{kg}$ de $\mathrm{PC}$} & VAC & $0,66 \mathrm{a}$ & $0,66 \mathrm{a}$ & $0,62 \mathrm{a}$ & $0,56 \mathrm{a}$ & 0,62 & 0,04 & 0,59 & 0,03 \\
\hline & NOV & $0,69 \mathrm{a}$ & $0,55 \mathrm{~b}$ & $0,56 \mathrm{a}$ & $0,56 \mathrm{a}$ & 0,59 & 0,05 & 0,04 & 0,03 \\
\hline \multirow[t]{2}{*}{$\mathrm{kg} / \mathrm{dia}$} & VAC & $3,51 \mathrm{a}$ & $3,47^{\mathrm{a}}$ & $3,09 \mathrm{a}$ & $2,81 \mathrm{a}$ & 3,22 & 0,04 & 0,99 & 0,25 \\
\hline & NOV & $2,83 \mathrm{a}$ & $2,30 \mathrm{~b}$ & $2,24 b$ & $2,37 \mathrm{a}$ & 2,43 & 0,31 & 0,17 & 0,25 \\
\hline \multicolumn{10}{|c|}{ Carboidratos não Fibrosos } \\
\hline \multirow[t]{2}{*}{$\mathrm{g} / \mathrm{kg}$ de $\mathrm{PC}$} & VAC & 14,1 & 15,1 & 14,8 & 13,9 & $14,5 \mathrm{a}$ & 0,69 & 0,39 & 0,09 \\
\hline & NOV & 14,8 & 12,6 & 13,6 & 13,5 & $13,7 \mathrm{a}$ & 0,55 & 0,32 & 0,09 \\
\hline \multirow[t]{2}{*}{ kg/dia } & VAC & $7,54 \mathrm{a}$ & $7,87 \mathrm{a}$ & $7,29 \mathrm{a}$ & $7,07 \mathrm{a}$ & 7,45 & 0,45 & 0,82 & 0,61 \\
\hline & NOV & $6,04 a$ & $5,24 \mathrm{~b}$ & $5,43 \mathrm{~b}$ & $5,70 \mathrm{a}$ & 5,60 & 0,86 & 0,81 & 0,61 \\
\hline \multicolumn{10}{|c|}{ Extrato Etéreo } \\
\hline \multirow[t]{2}{*}{$\mathrm{kg} / \mathrm{dia}$} & VAC & $0,30 \mathrm{a}$ & $0,26 a$ & $0,23 \mathrm{a}$ & $0,21 \mathrm{a}$ & 0,25 & 0,01 & 0,45 & 0,02 \\
\hline & $\mathrm{NOV}$ & $0,24 a$ & $0,17 \mathrm{~b}$ & $0,18 \mathrm{a}$ & $0,16 a$ & 0,19 & 0,05 & 0,19 & 0,02 \\
\hline \multicolumn{10}{|l|}{ GPD } \\
\hline \multirow[t]{2}{*}{$\mathrm{kg} / \mathrm{dia}$} & VAC & 1.42 & 1.46 & 1.23 & 1.15 & $1.32 \mathrm{a}$ & 0,29 & 0,98 & 0,21 \\
\hline & $\mathrm{NOV}$ & 1.49 & 1.49 & 1.56 & 1.59 & $1.53 \mathrm{a}$ & 0,71 & 0,98 & 0,21 \\
\hline
\end{tabular}

Médias na mesma coluna no mesmo parâmetro, seguidas de letras distintas, diferem entre si pelo teste de $\mathrm{F}$ a $5 \%$ de probabilidade de erro. ${ }^{\text {NS }}$ - não significativo; Xni = nível de glicerol. VAC: Vaca; NOV: Novilho.

O aumento dos níveis de inclusão de glicerol às dietas afetou a ingestão de EE pelas vacas e novilhos $(\mathrm{P}<0,05)$ (Tabela 3$)$. As vacas apresentaram redução no consumo de EE expresso em kg/dia, g/ $\mathrm{kgPC}^{0,75}$ e \% PC $(\mathrm{P}<0,05)$ com a inclusão de glicerol às dietas (Tabela 3 ).

O glicerol utilizado neste estudo apresentou $1,19 \%$ de EE, sendo menor que o valor médio de 3,97\% de EE do milho (VALADARES FILHO, 2000). Sendo assim, a substituição do milho pelo glicerol provocou menor participação desse nutriente nas dietas, consequentemente, diminuindo o seu consumo pelos animais.

Observa-se que, embora tenha ocorrido redução no consumo de $\mathrm{EE}$, as diferenças são de pequena magnitude e com pouca possibilidade de ocorrer alterações no desempenho em função desse nutriente. Diferente dos resultados do presente estudo, LAGE et al. (2010) verificaram que,com a inclusão de até $10,81 \%$ de glicerina bruta à dieta, o consumo de EE sofreu elevação. De acordo com os autores, tal elevação se deu pelo fato de a glicerina bruta utilizada ser de baixa qualidade e conter
46,48\% de ácidos graxos, indicando que a reação de transesterificação, na qual os ácidos graxos são separados do glicerol, foi incompleta e grande quantidade de ácidos graxos ficou contida na glicerina bruta.

Comparando o consumo de EE expresso em $\mathrm{kg} /$ dia e $\mathrm{g} / \mathrm{kgPC}^{0,75}$ das vacas em relação aos novilhos, observou-se que as vacas alimentadas com dietas contendo $6 \%$ de glicerol consumiram maior quantidade de $\mathrm{EE}$ que os novilhos $(\mathrm{P}<0,05)$. No entanto, não foram detectadas diferenças quando o consumo foi expresso em \%PC ( $\mathrm{P}>0,05)$. Conforme já comentado anteriormente, as alterações no consumo de MS foram as responsáveis pela alteração no consumo do EE.

A inclusão de glicerol às dietas não afetou (P> 0,05) o ganho de peso diário (GPD), independentemente do sexo dos animais (Tabela 3). Como as dietas fornecidas foram isoproteicas e isoenergeticas e como não foi observado efeito da inclusão de glicerol no CMS tanto de machos quanto de fêmeas, o GPD e o GPT também não foram afetados pelas dietas. Esse resultado já era esperado, 
uma vez que o desempenho animal é função direta do consumo de matéria seca digestível (MERTENS, 1994).

O GPD das vacas $(1,32 \mathrm{~kg} / \mathrm{dia})$ e dos novilhos $(1,53 \mathrm{~kg} /$ dia $)$ obtidos neste trabalho não diferiram entre si estatisticamente $(\mathrm{P}>0,05)$ e estão próximos ao GPD pretendido na formulação das dietas que foi de $1,30 \mathrm{~kg} /$ dia. Possivelmente, pelo fato de os animais partilharem da mesma condição ambiental no período pré-experimental, e por as fêmeas serem maiores e apresentarem maior exigência nutricional, as vacas tiveram menor atendimento das suas necessidades nutricionais que os novilhos apresentando, dessa forma, GPD similar ao dos machos.

Resultados de GPD semelhantes ao observado neste trabalho foram obtidos por $\mathrm{MACH}$ et al. (2009). Os autores observaram ganhos médios diário em seus animais de $1,36 \mathrm{~kg} /$ dia utilizando até $12 \%$ de glicerina bruta na terminação de novilhos da raça holandesa com ração contendo alto nível de grãos. No entanto, PARSONS et al. (2009), avaliando o desempenho produtivo de novilhas mestiças holandesas em confinamento, verificaram GPD máximo $(1,34 \mathrm{~kg} / \mathrm{dia})$, quando os animais apresentaram o maior consumo de MS $(8,88$ $\mathrm{kgMS} /$ dia) e consumiram ração com $2 \%$ de inclusão de glicerina bruta.

No entanto as respostas obtidas no presente estudo demonstram que o glicerol pode ser incluído nas dietas de machos e fêmeas leiteiros até o nível de $24 \%$ sem comprometer o GPD dos animais.

\section{CONCLUSÃO}

A inclusão de glicerol até $240 \mathrm{~g} / \mathrm{kg}$ de MS na dieta de vacas e novilhos castrados de aptidão leiteira não afeta o consumo de nutrientes e permite desempenho animal similar ao desempenho de animais alimentados com milho como principal fonte energética.

\section{REFERÊNCIAS}

ABDALLA, A. L.; SILVA FILHO, J. C.; GODOI, A. R.; CARMO, C. A.; EDUARDO, J. L. P. Utilização de subprodutos da indústria de biodiesel na alimentação de ruminantes. Revista Brasileira de Zootecnia, v.37, p.260-258, 2008 .

AMERICAN OIL CHEMISTS' SOCIETY - AOCS. Rapid determination of oil/fat utilizing high temperature solvent extraction. 2009. Available at: http://www.ankom.com/media/documents/

CrudeFat_0504_013009.pdf. Accessed on: 03 de agosto de 2012
ASSOCIAÇÃO BRASILEIRA DA INDÚSTRIA QUÍMICA - ABIQUIM. São Paulo, 2007. 1 CD ROM.

BANCO ORIGINAL. $1^{\text {a }}$ Pesquisa de Intenção de Confinamento Resultados Completos, http://www.bancomatone.com.br/uploads/INFORMACOES _FINANCEIRAS_RELATORIOS/Pesquisa\%20de\%20Inten $\% \mathrm{C} 3 \% \mathrm{~A} 7 \% \mathrm{C} 3 \% \mathrm{~A} 3 \mathrm{o} \% 20 \mathrm{de} \% 20$ Confinamento $\% 20 \mathrm{Banco} \%$ 20Original\%20-\%20Resultados\% 20Completos_.pdf Acesso em: 04 de setembro de 2012.

CHUNG, Y. H.; RICO, D.E; MARTINEZ, C. M.; CASSIDY, T. W.; NOIROT, V.; AMES, A.; VARGA, G. A. Effects of feeding dry glycerin to early postpartum holstein dairy cows on lactational performance and metabolic profiles.Journal Dairy Science, v.90, n.12, p.5682-5691, 2007 .

DEFRAIN, J.M.; HIPPEN, R.; KALSCHEUR, K.F.; JARDON, P.W. Feeding glycerol to transition dairy cows: effects on blood metabolites and lactation performance. JournalDairyScience, v.87, n. 12, p. 4195-4206, 2004.

DONKIN, S.S Glycerol from biodiesel production: the new corn for dairy cattle. Revista Brasileira de Zootecnia v.37, p.280-286, 2008. Suplemento Especial.

JOBIM, C.C; SANTOS, G.T. A qualidade da silagem como determinante da produção e da qualidade do leite. In: SANTOS, G.T; UHLIG, L.; BRANCO, A.F.; JOBIM, C.C.; DAMASCENO, J.C.; CECATO, U. Bovinocultura de leite: Inovação Tecnológica e Sustentabilidade. Maringá: Eduem, 2008. p.203-219.

FERREIRA, D.F. Sisvar versão 4.2. DEX/UFLA, 2003.

LAGE, J.F; PAULINO, P.V.R.,PEREIRA, L.G.R.; VALADARES FILHO, S. C. OLIVEIRA, A.S; DETMANN, E.; SOUZA, N.K. P.; LIMA, J.C.M. Glicerina bruta na dieta de cordeiros terminados em confinamento. Pesquisa Agropecuária Brasileira, v.45, n.9, p.1012-1020, 2010.

MACH, N.; BACH, A.; DEVANT, M. Effects of crude glycerin supplementation on performance and meat quality of Holstein bulls fed high-concentrate diets. Journal Animal Science, v.87, n.2, p. 632-638. 2009.

MARCONDES, M.I.; VALADARES FILHO, S. C.; PAULINO, P.V.R.; DETMANN, E.; PAULINO, M.F.; DINIZ, L.L.; SANTOS, T.R. Consumo e desempenho de animais alimentados individualmente ou em grupo e características de carcaça de animais Nelore de três classes sexuais. Revista Brasileira de Zootecnia, v.37, n.12, p.2243-2250, 2008.

MERTENS, D.R. Creating a system for meeting the fiber requirements of dairy cows. Journal Dairy Science, $n$. 80, p.1463-1481, 1997.

MERTENS, D.R. Regulation of forage intake. In: FAHEY Jr., G.C. (Ed.) Forage quality, evaluation and utilization. Madison: American Society of Agronomy, p.450-493, 1994.

MOTTA, C.J. A.; SILVA, C.X .A .; GONÇALVES, V.L.C. Gliceroquímica: novos produtos e processos a 
partir da glicerina de produção de biodiesel. Química Nova, v.32, n.3, p.639-648, 2009.

MUSSELMAN, A. F.; VAN EMON, M.L.; GUNN, P.J.; RUSK, C.P.; NEARY,M.K.; LEMENAGER, R.P.; LAKE, S.L. Effects of crude glycerin on feedlot performance and carcass characteristics of market lambs. Proceedings, Western Section, American Society of Animal Sciences, v.59, p.353-355, 2008.

NATIONAL RESEARCH COUNCIL - NRC. Nutrient requeriments of dairy cattle. 7 th ed. Washinton: National Academy of Science, 2001. 408 p.

NATIONAL RESEARCH COUNCIL - NRC. Nutrient requirements of beef cattle. 7 th ed. Washington: National Academy of Science, 2000. 248 p.

PARSONS, G.L.; SHELOR, M. K.; J. S. DROUILLARD, J. S. Performance and carcass traits of finishing heifers fed crude glycerin. Journal Animal Science, v.87, p.653-657, 2009.

ROCHA, F.C.; GARCIA, R.; PAULA FREITAS, A.W.; BERNARDINO, F.S.; VALADARES FILHO, S.C.; ROCHA, G.C. Valor energético de dietas contendo diferentes níveis de casca de café para bovinos e ovinos. Acta Scientiarum Animal Sciences, v.28, n. 1, p. 81-87, 2006.

SILVA, D.J. ; QUEIROZ, A.C. Análise de alimentos: Métodos químicos e biológicos. $3^{\mathrm{a}}$ ed. Universidade Federal de Viçosa, 2002, 165p.

SIMAS, J. M. C.; PIRES, A. V.; SUSIN, I. ; SANTOS, F. A. P. ; MENDES, C. Q.; OLIVEIRA JR., R.C. ;
FERNANDES, J. J. R.. Efeitos de fontes e formas de processamento do amido na utilização de nutrientes e parâmetros ruminais de vacas em lactação. Arquivo Brasileiro de Medicina Veterinária e Zootecnia, v. 60, p. 1128-1134, 2008.

SNIFFEN, C.J.; O'CONNOR, J.D.; VAN SOEST, P.J.; FOX, D.G.; RUSSEL, J.B. A net carbohydrateandprotein system for evaluatingcattle diets: II. Carbohydrate and protein availability. Journal of Animal Science, v.70, p.3562-3577, 1992.

SWIATKIEWICZ, S.; KORELESKI, J. Effect of crude glycerin level in the diet of laying hens on egg performance and nutrient utilization. Poultry Science, v. 88, p.615-619, 2009.

TRABUE, S.; SCOGGIN, K.; TJANDRAKUSUMA, S.;RASMUSSEN, M.A.; REILLY, P.J., Ruminal fermentation of propylene glycol and glycerol. Journal of Agricultural and Food Chemistry, v. 55, p. 7043-7051, 2007.

VALADARES FILHO, S.C., MACHADO, P.A.S., CHIZZOTTI, M.L. et al. CQBAL 3.0. Tabelas Brasileiras de Composição de Alimentos para Bovinos. Disponível em www.ufv.br/cqbal. Acesso em 28 de outubro de 2012$10-28$

VAN SOEST, P.J.; ROBERTSON, J.B.; LEWIS, B.A. Symposium: carbohydratemetodology, metabolism, andnutritionalimplications in dairycattle. Journal of Dairy Science, Champaign, v. 74, n. 10, p.3583-3597, 1991.

Protocolado em: 23 maio 2012. Aceito em 10 set. 2012. 